\title{
Human Listeriosis Outbreaks Linked to Dairy Products in Europe*
}

\author{
J. Lundén, R. Tolvanen, and H. Korkeala \\ Department of Food and Environmental Hygiene, \\ University of Helsinki, Finland
}

\section{ABSTRACT}

Dairy products have been associated with approximately half of the reported listeriosis outbreaks in Europe. The listeriosis outbreaks have mostly been linked to consumption of raw milk or products made of unpasteurized milk. Outbreaks, such as in Switzerland in 1983 to 1987 caused by unpasteurized soft cheese, in Austria in 1986 by unpasteurized milk, and in France in 1995 by a Brie-type cheese made of unpasteurized milk demonstrate the risks involved in the consumption of raw milk or soft cheeses made of unpasteurized milk.

The pasteurization of raw milk, which destroys Listeria monocytogenes, does not eliminate later risk of $L$. monocytogenes contamination in dairy products. The outbreak in Finland from 1998 to 1999, with butter as the source, shows that dairy products made of pasteurized milk may become contaminated in subsequent stages of production with $L$. monocytogenes.

Extensive work has been ongoing in several European countries during the last decade to prevent outbreaks and decrease the incidence of listeriosis. This work has included preventive measures in food processing plants, consumer education, and early detection of outbreaks. A marked reduction has occurred in the incidence of listeriosis in some of these countries during the 1990s, suggesting a relationship between preventive measures and reduction in listeriosis.

(Key words: listeriosis, dairy product, outbreak)

Abbreviation key: PFGE = pulsed-field gel electrophoresis.

\section{INTRODUCTION}

Milk and other dairy products have been implicated in about half of all the listeriosis outbreaks and in several sporadic cases in Europe (Ryser, 1999; De Buyser et al.,

Received July 7, 2003.

Accepted October 1, 2003. fi.

Corresponding author: J. Lundén; e-mail: janne.lunden@helsinki.

*Presented at a symposium titled "Listeria monocytogenes: A Model Pathogen for Farm-to-Table Intervention" at the ADSA-ASAS Joint Annual Meeting, June 2003, Phoenix, AZ.
2001). Listeriosis outbreaks due to dairy products have considerable health implications. Investigated outbreaks to date have resulted in almost 400 cases and over 60 fatalities in Europe. The consumption of dairy products in EU countries is substantial, averaging $132 \mathrm{~kg}$ per person annually. Milk and other dairy products, are consumed by all age groups, including those populations at risk for contracting listeriosis (European Commission, 2000).

Dairy products have been linked to both invasive and noninvasive listeriosis outbreaks. Invasive listeriosis causes meningoencephalitis, encephalitis, sepsis, and abortions and has a high mortality rate (20 to 30\%) (Gellin et al., 1991; Goulet and Marchetti, 1996; Goulet et al., 2001). Invasive listeriosis occurs mainly in people belonging to a specific risk group, which includes the young, old, pregnant, and immunocompromized persons (McLauchlin, 1990b; Gellin et al., 1991). Infection during pregnancy can lead to abortion, stillbirth, or septicemia of the neonate, even though the pregnant woman may only experience flu-like symptoms (McLauchlin, 1990a). The noninvasive disease causes fever, diarrhea, muscle pain, headache, nausea, vomiting, and abdominal pain in healthy adults (Salamina et al., 1996; Miettinen et al., 1999b; Aureli et al., 2000).

Listeriosis outbreaks have been associated with dairy products manufactured from raw milk (Büla et al., 1995; Goulet et al., 1995). The consumption of raw milk products, especially soft cheeses, is therefore clearly a risk factor. However, the production of soft cheeses from raw milk is still employed and may result in new listeriosis outbreaks (Carrique-Mas et al., 2003). On the other hand, an outbreak caused by a product made from pasteurized milk showed that raw milk products are not the only risk products (Lyytikäinen et al., 2000; Maijala et al., 2001).

Preventive measures have been taken on several fronts, and the incidence of listeriosis has decreased (Goulet et al., 2001; National Public Health Institute, 2003; Lukinmaa et al., 2003). However, recent listeriosis outbreaks due to dairy products (Lyytikäinen et al., 2000; Carrique-Mas et al., 2003) show that these preventive measures have not been able to fully prevent outbreaks.

\section{LISTERIA MONOCYTOGENES IN DAIRY PRODUCTS}

Listeria monocytogenes can be found in raw milk and in a variety of dairy products (Table 1 ). L. monocytogenes 
Table 1. Prevalence of Listeria monocytogenes in different types of dairy products in European countries.

\begin{tabular}{llll}
\hline & $\begin{array}{l}\text { Prevalence } \\
(\%) \text { of } \\
\text { Listeria } \\
\text { monocytogenes }\end{array}$ & Country of origin & Reference \\
Product & 4.4 & The Netherlands & Beckers et al., 1987 \\
\hline Raw milk & 3.6 & England and Wales & Greenwood et al., 1991 \\
Raw milk & 1 & Sweden & Waak et al., 2002 \\
Raw milk & 65 & France & Beckers et al., 1987 \\
Soft cheese made of raw milk & 8.2 & England and Wales & Greenwood et al., 1991 \\
Soft ripened cheese & 1.1 & England and Wales & Greenwood et al., 1991 \\
Soft unripened cheese & 6 & Italy, Germany, Austria, and France & Rudolf and Scherer, 2001 \\
Soft cheese & 8 & France, Germany, and Italy & Loncarevic et al., 1995 \\
Soft or semi soft cheese & 1.5 & Italy, Germany, Austria, and France & Rudolf and Scherer, 2001 \\
Semi soft cheese & 4 & England and Wales & Greenwood et al., 1991 \\
Hard cheese & 0.5 & Italy, Germany, Austria, and France & Rudolf and Scherer, 2001 \\
Hard cheese & & Finland & Miettinen et al., 1999a \\
Ice cream & & &
\end{tabular}

is commonly found in raw milk samples and soft cheeses. Listeria monocytogenes tolerates harsh conditions and may therefore survive or grow in different types of foods. The organism can grow in low temperatures $(-1.5$ to $45^{\circ} \mathrm{C}$ ) (Seeliger and Jones, 1986; Junttila et al., 1988; Hudson et al., 1994) and in a wide $\mathrm{pH}$ range (4.3 to 9.1) (Farber et al., 1989). It can also grow in salt concentrations of up to 10 to $14 \%$ (McClure et al., 1989; Farber et al., 1992) and tolerates low water activity (Nolan et al., 1992), which enables survival even in products with a very high fat content such as semi-hard cheeses (Bachmann and Spahr, 1995). However, the prevalence of $L$. monocytogenes varies in different types of cheeses. In soft and semi-soft cheeses, the water activity is higher than in hard cheeses (Rudolf and Scherer, 2001), thus allowing growth of $L$. monocytogenes. In mold cheeses, the $\mathrm{pH}$ approaches neutral levels during ripening, permitting the growth of L. monocytogenes (Ryser and Marth, 1987). During the production of fermented dairy products, the combination of competition with the starter culture, low water activity, and a low $\mathrm{pH}$ prevent the survival and growth of $L$. monocytogenes (Morgan et al., 2001).

\section{LISTERIOSIS IN EUROPE}

About 0.2 to 0.8 cases of listeriosis per 100,000 persons occur annually in developed countries (Gellin et al., 1991; McLauchlin, 1996; Anonymous, 2001; Lukinmaa et al., 2003) (Table 2). This results in 1600 to 8400 cases in Europe per year with 320 to 2500 deaths. The wide range in the incidences may result because of differences in the notification systems or due to outbreaks, which may markedly increase the number of cases. The number of reported cases related to outbreaks during 1991 to 2001 in Europe was 2065, i.e., 188 cases per year. The exact number of cases related to the outbreaks is unknown but is probably higher than the reported figure (Lukinmaa et al., 2003; Sauders et al., 2003). Lukinmaa et al. (2003) investigated the relatedness of $314 \mathrm{~L}$. monocytogenes strains of clinical origin by serotyping and pulsed-field gel electrophoresis (PFGE) typing. The material represented clinical strains from invasive listeriosis isolated from 1990 to 2001. The authors observed that during the 1990s clusters of cases of the same PFGE type or of groups of closely related PFGE types were seen every year. Similar findings were made by Sauders et al. (2003) in New York State between 1996 and 2000. These results indicate that some of the sporadic cases may have in fact been part of unrecognized outbreaks. The noninvasive disease form and possible noninvasive disease outbreaks are also probably underdiagnosed because $L$. monocytogenes is not routinely screened from stool samples and the syndrome is usually self-resolving (Aureli et al., 2000; Schlech, 2000).

\section{LISTERIOSIS OUTBREAKS LINKED TO DAIRY PRODUCTS}

Dairy products have served as vehicles of Listeria monocytogenes in several listeriosis outbreaks in Europe (Table 3). The number of outbreaks associated with dairy products accounts for about half of the total number of outbreaks associated with all food types (Table 4). In the majority of cases, these outbreaks have been linked to consumption of raw milk or products produced from raw milk such as soft cheeses. Although the first scientifically proven listeriosis outbreak transmitted by food occurred in 1981 (Schlech et al., 1983), raw milk has been suspected of causing outbreaks earlier. A massive occurrence of listeriosis, which was believed transmitted by raw milk, was observed in Halle, Germany, from 1949 to 1957 (Seeliger, 1961). Since then, several outbreaks connected with milk or dairy products have been identified.

Soft cheese made of raw milk was determined to be the cause of listeriosis outbreaks in Switzerland between 1983 and 1987. An elevation in the occurrence of listeri- 
Table 2. Incidence of listeriosis cases in some European countries.

\begin{tabular}{llll}
\hline & $\begin{array}{l}\text { Incidence } \\
\text { per 100,000 } \\
\text { persons }\end{array}$ & Year & Reference \\
\hline Country & 0.2 & $1994-1996$ & Anonymous, 1997 \\
England and Wales & 0.2 & $1996-2000$ & Anonymous, 2001 \\
Iceland & 0.4 & $2000-2002$ & National Public Health Institute, 2003 \\
Finland & 0.4 & $1996-2000$ & Anonymous, 2001 \\
Norway & 0.5 & $1996-2000$ & Anonymous, 2001 \\
Sweden & 0.5 & 1997 & Goulet et al., 2001 \\
France & 0.7 & 2002 & Public Health Agency, 2002 \\
Latvia & 0.8 & $1996-2000$ & Anonymous, 2001 \\
Denmark & & & \\
\hline
\end{tabular}

osis was observed during wintertime. The L. monocytogenes phagotypes were different from the usual types isolated in the area. The same $L$. monocytogenes phagotype that was identified in patients was also found in soft cheeses, which were only produced in wintertime, and in food plant environments. A total of 122 cases were diagnosed between 1983 and 1987 (Büla et al., 1995).

In Austria, 39 cases of listeriosis occurred in 1986. The epidemiological survey of 28 culture-confirmed cases revealed that some of the patients had consumed raw milk and organic vegetables. It was concluded that raw milk and vegetables were possible sources of infection (Allerberger and Guggenbichler, 1989).

In Denmark, 69 cases of listeriosis were diagnosed between 1989 and 1990, with 26 cases being caused by the same phagotype. The outbreak was associated with 2 vehicles. Epidemiological studies revealed an association between listeriosis and blue-mold cheese, although $L$. monocytogenes was not isolated from the cheese. Dairy control samples, by contrast, showed that the epidemic phagotype was present in hard cheese during this period (Jensen et al., 1994).

In 1995, there was a listeriosis outbreak in France, and 37 cases were associated with consumption of a Brietype cheese made of raw milk (Goulet et al., 1995; Rocourt et al., 1997). The same $L$. monocytogenes PFGE type isolated from patients was traced to 4 Brie-type cheese sample isolates received earlier that year by the National Reference Center. Epidemiological studies indicated that all patients had consumed Brie-type cheese (Goulet et al., 1995). A similar type of epidemic caused by soft cheese made of raw milk occurred in France in 1997. Fourteen epidemic-related cases were recognized. Epidemiological investigations implicated 2 cheeses manufactured by the same establishment as the vehicles of the outbreak (Jacquet et al., 1998).

In 2001, 48 people suffered from febrile gastroenteritis after consuming on-farm manufactured dairy products from a summer farm in Sweden. The fresh cheese was made of raw milk. The $L$. monocytogenes isolates were genotyped with restriction enzyme analysis, and typing results revealed that all patient and dairy product isolates were identical. Epidemiological investigations showed that eating any cheese produced at this farm was associated with disease. In addition to $L$. monocytogenes, verotoxigenic and enterotoxigenic Escherichia coli gene markers were isolated from 6 and 1 stool samples, respectively, and presumptive $E$. coli and coagulase-negative staphylococci from dairy products. Although the most likely cause of the outbreak was $L$. monocytogenes, the possibility of mixed etiology could not be ruled out (Carrique-Mas et al., 2003).

Contaminated butter made of pasteurized milk was observed to be the cause of a listeriosis outbreak in Fin-

Table 3. Reported listeriosis outbreaks in Europe caused by milk or dairy products.

\begin{tabular}{|c|c|c|c|c|c|}
\hline Year & Country & Product type & $\begin{array}{c}\text { Number of } \\
\text { cases (deaths) }\end{array}$ & Serotype & Reference \\
\hline 1949-1957 & Germany & Raw milk & about 100 & $\mathrm{NA}^{1}$ & Seeliger, 1961 \\
\hline 1983-1987 & Switzerland & Soft cheese ${ }^{2}$ & $122(33)$ & $4 \mathrm{~b}$ & Büla et al., 1995 \\
\hline 1986 & Austria & Raw milk/vegetables & $28(5)$ & $1 / 2 \mathrm{a}$ & Allenberger and Guggenbichler, 1989 \\
\hline $1989-1990$ & Denmark & Blue-mold cheese/hard cheese & $26(6)$ & $4 \mathrm{~b}$ & Jensen et al., 1994 \\
\hline 1995 & France & Soft cheese ${ }^{2}$ & $37(11)$ & $4 \mathrm{~b}$ & Goulet et al., 1995; Rocourt et al., 1997 \\
\hline 1997 & France & Soft cheese $^{2}$ & 14 & $4 \mathrm{~b}$ & Jacquet et al., 1998 \\
\hline 1998-1999 & Finland & Butter $^{2}$ & $25(6)$ & $3 a$ & Lyytikäinen et al., 2000 \\
\hline 2001 & Sweden & Soft cheese $\mathrm{c}^{2,3}$ & 33 & $1 / 2 \mathrm{a}$ & Carrique-Mas et al., 2003 \\
\hline
\end{tabular}

${ }^{1}$ Data not available.

${ }^{2}$ Vehicle of infection identified.

${ }^{3}$ Mixed etiology possible. 
LISTERIOSIS OUTBREAKS AND DAIRY PRODUCTS

Table 4. Reported listeriosis outbreaks in Europe according to food type.

\begin{tabular}{lllll}
\hline Food type & Year & Country & Serotype & Reference \\
\hline Diary & $1949-1957$ & Germany & NA $^{1}$ & Seeliger, 1961 \\
& $1983-1987$ & Switzerland & $4 \mathrm{~b}$ & Büla et al., 1995 \\
& 1986 & Austria & $1 / 2 \mathrm{a}$ & Allenberger and Guggenbichler, 1989 \\
& $1989-1990$ & Denmark & $4 \mathrm{~b}$ & Jensen et al., 1994 \\
& 1995 & France & $4 \mathrm{~b}$ & Goulet et al., 1995 \\
& 1997 & France & $4 \mathrm{~b}$ & Jacquet et al., 1998 \\
& $1998-1999$ & Finland & $3 \mathrm{a}$ & Lyytikäinen et al., 2000 \\
Meat & 2001 & Swenden & $1 / 2 \mathrm{a}$ & Carrique-Mas et al., 2003 \\
& $1987-1989$ & United Kingdom & $4 \mathrm{~b}$ & McLauchlin et al., 1991 \\
& 1992 & France & $4 \mathrm{~b}$ & Goulet et al., 1993; Jacquet et al., 1995 \\
& 1993 & France & $4 \mathrm{~b}$ & Goulet et al., 1998 \\
Fish & $1999-2000$ & France & $4 \mathrm{~b}$ & De Valk et al., 2001 \\
& $1994-1995$ & Swenden & $4 \mathrm{~b}$ & Ericsson et al., 1997 \\
Vegetable & 1997 & Finland & $1 / 2 \mathrm{a}$ & Miettinen et al., 1999b \\
& 1993 & Italy & $1 / 2 \mathrm{~b}$ & Salamina et al., 1996 \\
& 1997 & Italy & $4 \mathrm{~b}$ & Aureli et al., 2000 \\
\hline
\end{tabular}

${ }^{1}$ Data not available.

land in 1998 to 1999 (Lyytikäinen et al., 2000). The delivery of butter from a dairy plant to highly susceptible people at a hospital started in June 1998. In total 25 listeriosis cases, of which 6 resulted in death were caused by an identical PFGE type from June 1998 to April 1999. The same PFGE type was found in the butter served at the hospital. The recall of the butter stopped the outbreak. Investigations carried out in the dairy plant revealed that the butter and the plant were contaminated with the outbreak strain.

\section{DISTRIBUTION OF SEROTYPES}

The most common serotype in European listeriosis outbreaks has been $4 \mathrm{~b}$. The distribution of serotypes in outbreaks caused by vehicles other than dairy products appears to be similar to that of dairy product-linked outbreaks (Table 4). However, there is a discrepancy between clinical isolates and food isolates as serotype 4b is not the most common serotype in food isolates (Miettinen et al., 1999a, Autio et al., 2002; Lundén et al., 2003). It has been suggested that serotype $4 \mathrm{~b}$ may have an increased virulence, but no definite association between virulence and serotype has been established (Kathariou, 2002). However, several studies show that the distribution of serotypes in listeriosis cases has changed during the 1990s. The number of cases caused by serotype $1 / 2 \mathrm{a}$ has increased, while that by serotype $4 \mathrm{~b}$ has decreased. Between 1990 and 2001, the incidence of serotype 1/2a increased from 22 to $67 \%$ in Finland (Lukinmaa et al., 2003). Similar findings have been made in several other European countries (Gerner-Smidt et al., 1995; McLauchlin and Newton, 1995; Tham et al., 2001; Hjaltested et al., 2002). Serogroup 1/2 causes about half of the sporadic cases in Finland and Denmark (Anonymous, 2001). In Iceland, 53\% of the 15 laboratory-confirmed cases of listeriosis from 1993 to 2000 were determined to be serotype $1 / 2 \mathrm{~b}$ and $40 \%$ serotype $1 / 2 \mathrm{a}$ (Anonymous, 2001). The 2 most recent dairy product-linked outbreaks in Finland and Sweden were also caused by serotypes other than $4 \mathrm{~b}$ (Table 4 ). No apparent reason to the change in the distribution of serotypes in listeriosis cases has been detected. However, the serogroup $1 / 2$ is the leading serogroup in foods (Miettinen et al., 1999a; Autio et al., 2002; Lundén et al., 2003), and the discrepancy between food and clinical isolates is therefore not that apparent anymore.

\section{SURVEILLANCE IN EUROPEAN COUNTRIES}

Surveillance systems for $L$. monocytogenes have been developed in several European countries (Rocourt et al., 2000; Anonymous, 2001; Lukinmaa et al., 2003). A surveillance system lays the foundation for an effective prevention program. Surveillance in many European countries is based on a notification system. Notification is mandatory in some countries such as Finland and France (Lyytikäinen, 2000; De Valk et al., 2001). The notification system, in general, includes the reporting of culture-confirmed cases of listeriosis to national health authorities. The L. monocytogenes isolates are further subtyped by serotyping and PFGE typing, which enables the identification of outbreaks (Rocourt et al., 2000). The PFGE profiles of different strains are collected in a database library, which in turn enables rapid detection of clusters of cases (Lukinmaa et al., 2003).

The surveillance does not only include the human cases, but also the dairy processing plants. Food processing plants including dairy plants in the EU countries are obligated to perform surveillance of $L$. monocytogenes, which includes the establishment of a sampling plan for L. monocytogenes based on risk assessment. In 
addition to the samples taken by the plant the authorities sample the plant and the products on a regular basis (National Veterinary and Food Research Institute, 1999).

The surveillance of human cases enables recognition of outbreaks but the data does not reveal the sources of infection. Therefore, e.g., in Finland, food isolates from the surveillance samples are also characterized by serotyping and PFGE typing. The PFGE profiles of human, food, and food production environment origin are compared in a bilateral computer-based network, which may help in recognizing sources of infections (Rantala et al., 2001; Lukinmaa et al., 2003).

\section{PREVENTION IN EUROPEAN COUNTRIES}

Prevention of listeriosis is considered to be of major importance as the mortality is very high. Extensive work has been done to lower the incidence of listeriosis in Europe. Reducing the incidence of listeriosis includes preventive measures in food processing plants with a focus on postprocessing hygiene, consumer education, and early detection of outbreaks (Lyytikäinen et al., 2000; Rocourt et al., 2000; Schlech, 2000; Lukinmaa et al., 2003). A marked reduction in the incidence of listeriosis has occurred in some European countries during the 1990s (Goulet et al., 2001; National Public Health Institute, 2003; Lukinmaa et al., 2003). The decrease from 1987 to 1997 in the incidence of invasive listeriosis was estimated to be 68\% in France (Goulet et al., 2001). In Finland, the incidence of listeriosis has decreased from 0.9 in 1997 to 0.4 per 100,000 persons in 2002 (National Public Health Institute, 2003).

One of the most important targets in the prevention of listeriosis is the dairy processing plants. If the prevalence of $L$. monocytogenes is successfully reduced in dairy products, the risk for acquiring listeriosis from those products will also be reduced. Prevention in dairy processing plants has been directed at improving postprocessing hygiene (Miettinen et al., 1999a; Goulet et al., 2001). Although the pasteurization of raw milk $\left(71.7^{\circ} \mathrm{C}\right.$ or $161^{\circ} \mathrm{F}$ for $15 \mathrm{~s}$ ) is considered an efficient and safe process in the elimination of $L$. monocytogenes (World Health Organization Working Group, 1998), the product may become contaminated subsequent to heat treatment. Thus, pasteurization of raw milk alone does not eliminate the risk of $L$. monocytogenes in dairy products. The earlier mentioned outbreak with butter as a source provides an example of a pasteurized dairy product acting as a vehicle for L. monocytogenes (Lyytikäinen et al., 2000; Maijala et al., 2001). In this case, the postprocessing equipment, including a packaging machine and a screw conveyor, were contaminated with the outbreak strain. There was also evidence showing possible persistence of the strain in the dairy plant. Persistence of $L$. monocytogenes in dairy plants is not uncommon (Unnerstad et al., 1996; Miettinen et al., 1999a), with processing machines typically preserving the contaminant (Miettinen et al., 1999a). Hygiene of postprocessing machines is therefore critical in controlling $L$. monocytogenes (Autio et al., 1999; Miettinen et al., 1999a; Lundén et al., 2002) and should include regular dismantling of the machines (Lundén et al., 2002).

Consumers, particularly pregnant or immunocompromized persons have been informed about risk products. Dairy products associated with listeriosis outbreaks, such as raw milk and raw dairy products, are categorized as risk products, which should not be consumed by susceptible people. However, the role of consumer education in France in the prevention of listeriosis has not been found to be substantial. Preventive measures at food processing plants were likely to be of much greater importance (Goulet et al., 2001).

Early detection of a listeriosis outbreak and efficient intervention are important in preventing the epidemic from continuing. Early detection of an outbreak is only possible with a real-time notification system and continuous typing of human isolates (Lyytikäinen et al., 2000). The importance of continuous typing in recognition of outbreaks is illustrated by Lukinmaa et al. (2003), which observed several clusters by retrospective typing of clinical isolates. Typing of food isolates and comparison with clinical isolates may also lead authorities to contaminated food processing plants (Lukinmaa et al., 2003). However, in addition to typing results, epidemiological evidence is needed for the incrimination of a food or a food processing plant (Autio et al., 2002). The spread of contaminated food products to different countries enables international outbreaks. Recognition of international outbreaks requires an international real-time monitoring system of clinical isolates, such as PulseNet in the United States (Swaminathan et al., 2001).

\section{CONCLUSIONS}

Dairy products are important vehicles of $L$. monocytogenes, regularly causing listeriosis outbreaks in Europe. Particularly, the consumption of raw milk or products made of raw milk has caused several listeriosis outbreaks resulting in several hundred cases. Raw milk and raw milk products are therefore clear risk factors and people that are susceptible for acquiring listeriosis should not consume such products. Information about the risks involved in consuming unpasteurized milk or milk products should also be provided continuously.

The importance of postprocessing hygiene has been emphasized in the listeriosis outbreak caused by butter. Good manufacturing and hygiene practices, particularly maintaining hygiene of processing machines, are the 
keys in preventing $L$. monocytogenes contamination. The authorities have an important role in checking the hygiene in dairy plants and in assessing and updating the in-house control plan including sampling protocols of $L$. monocytogenes. It is also equally important to notice that products, which may be subjected to postprocessing contamination should be reheated before consumption by highly immunocompromized persons in order to eliminate possible contamination.

Several European countries have a national surveillance system with continuous genotyping of clinical strains enabling detection of listeriosis outbreaks. Retrospective genotyping of clinical isolates have revealed that listeriosis outbreaks have probably been more common than previously detected. Some countries genotype also food isolates which enables the comparison of food and clinical isolates. This may help in recognizing the source of the outbreak. There is an increasing need for the detection of multinational outbreaks. The detection of multinational outbreaks requires the development of a standardized international surveillance system; design of such a system is currently under way.

\section{ACKNOWLEDGMENTS}

This work was supported by the Walter Ehrström Foundation.

\section{REFERENCES}

Allerberger, F., and J. P. Guggenbichler. 1989. Listeriosis in Austriareport of an outbreak in 1986. Acta Microbiol. Hung. 36:149-152.

Anonymous. 1997. Listeriosis in England and Wales: 1983 to 1996. Commun. Dis. Rep. 7:95.

Anonymous. 2001. Nordic Workshop on Listeria monocytogenes in Copenhagen 26th and 27th September, 2001. Copenhagen, Sweden.

Aureli, P., G. C. Fiorucci, D. Caroli, G. Marchiaro, O. Novara, L. Leone, and S. Salmaso. 2000. An outbreak of febrile gastroenteritis associated with corn contaminated by Listeria monocytogenes. N. Engl. J. Med. 342:1236-1241.

Autio, T., S. Hielm, M. Miettinen, A.-M. Sjöberg, K. Aarnisalo, J. Björkroth, T. Mattila-Sandholm, and H. Korkeala. 1999. Sources of Listeria monocytogenes contamination in a cold-smoked rainbow trout processing plant detected by pulsed-field gel electrophoresis typing. Appl. Environ. Microbiol. 65:50-155.

Autio, T., J. Lundén, M. Fredriksson-Ahomaa, J. Björkroth, A.-M. Sjöberg, and H. Korkeala. 2002. Similar Listeria monocytogenes pulsotypes detected in several foods originated from different sources. Int. J. Food Microbiol. 77:83-90.

Bachmann, H. P., and U. Spahr. 1995. The fate of potentially pathogenic bacteria in Swiss hard and semihard cheeses made from raw milk. J. Dairy Sci. 78:476-483.

Beckers, H. J., P. S. S. Soentoro, and E. H. M. Delfgou-van Asch. 1987. The occurrence of Listeria monocytogenes in soft cheeses and raw milk and its resistance to heat. Int. J. Food Microbiol. 4:249-256.

Büla, C. J., J. Bille, and M. P. Glauser. 1995. An epidemic of foodborne listeriosis in Western Switzerland: Description of 57 cases involving adults. Clin. Infect. Dis. 20:66-72.

Carrique-Mas, J. J., I. Hökeberg, Y. Andersson, M. Arneborn, W. Tham, M.-L. Danielsson-Tham, B. Osterman, M. Leffler, M. Steen, E. Eriksson, and J. Giesecke. 2003. Febrile gastroenteritis after eating on-farm manufactured fresh cheese - an outbreak of listeriosis? Epidemiol. Infect. 130:79-86.
De Buyser, M.-L., B. Dufour, M. Maire, and V. Lafarge. 2001. Implication of milk and milk products in food-borne diseases in France and in different industrialised countries. Int. J. Food Microbiol. 67:1-17.

De Valk, H., V. Vaillant, C. Jacquet, J. Rocourt, F. Le Querrec, F. Stainer, N. Quelquejeu, O. Pierre, V. Pierre, J.-C. Desenclos, and V. Goulet. 2001. Two consecutive nationwide outbreaks of listeriosis in France, October 1999-February 2000. Am. J. Epidemiol. 154:944-950.

Ericsson, H., A. Eklöw, M.-L. Danielsson-Tham, S. Loncarevic, L.-O. Mentzing, I. Persson, H. Unnerstad, and W. Tham 1997. An outbreak of listeriosis suspected to have been caused by rainbow trout. J. Clin. Microbiol. 35:2904-2907.

European commission. 2000. Healthy food for Europe's citizens. The European union and food quality. Europe on the move series. Office for Official Pub. Euro. Communities, Luxembourg.

Farber, J. M., G. W. Sanders, S. Dunfield, and R. Prescott. 1989. The effect of various acidulants on the growth of Listeria monocytogenes. Lett. Appl. Microbiol. 9:181-183.

Farber, J. M., F. Coates, and E. Daley. 1992. Minimum water activity requirements for the growth of Listeria monocytogenes. Lett. Appl. Microbiol. 15:103-105.

Gellin, B. G., C. V. Broome, W. F. Bibb, R. E. Weaver, S. Gaventa, and L. Mascola. 1991. The epidemiology of listeriosis in the United States-1986. Listeriosis Study Group. Am. J. Epidemiol. 133:392-401.

Gerner-Smidt, P., M. Weischer, A. Jensen, and W. Fredriksen. 1995. Listeriosis in Denmark—results of a 10-year survey. Page 472 in XII International Symposium on Problems of Listeriosis. Promaco Conventions Pty Ltd., Perth, Western Australia, Australia.

Goulet, V., C. Jacquet, V. Vaillant, I. Rebière, E. Mouret, C. Lorente, E. Maillot, F Staïner, and J. Rocourt. 1995. Listeriosis from consumption of raw-milk cheese. Lancet 345:1581-1582.

Goulet, V., A. Lepoutre, J. Rocourt, A. L. Courtieu, P. Dehaumont, and P. Veit. 1993. Epidémie de listériose en France-bilan final et résultats de l'enquête épidémiologique. Bull. Epidémiol. Hebdomadaire 4:13-14.

Goulet, V., and P. Marchetti. 1996. Listeriosis in 225 non-pregnant patients in 1992: Clinical aspects and outcome in relation to predisposing conditions. Scand. J. Infect. Dis. 28:367-374.

Goulet, V., J. Rocourt, I. Rebiere, C. Jacquet, C. Moyse, P. Dehaumont, G. Salvat, and P. Veit. 1998. Listeriosis outbreak associated with the consumption of rillettes in France in 1993. J. Infect. Dis. 177:155-160.

Goulet, V., H. de Valk, O. Pierre, F. Stainer, J. Rocourt, V. Vaillant, C. Jacquet, and J.-C. Desenclos. 2001. Effect of prevention measures on incidences of human listeriosis, France, 1987-1997. Emerg. Infect. Dis. 7:983-989.

Greenwood, M. H., D. Roberts, and P. Burden. 1991. The occurrence of Listeria species in milk and dairy products: a national survey in England and Wales. Int. J. Food Microbiol. 12:197-206.

Hjaltested, E. K., S. Guǒmundsdóttir, K. Jónsdóttir, K. G. Kristinsson, O. Steingrímsson, and M. Kristjánsson. 2002. Listeriosis in Iceland, 1978-2000: a description of cases and molecular epidemiology. Scand. J. Infect. Dis. 34:735-741.

Hudson, J. A., S. J. Mott, and N. Penney. 1994. Growth of Listeria monocytogenes, Aeromonas hydrophila, and Yersinia enterocolitica on vacuum and saturated carbon dioxide controlled atmospherepackaged sliced roast beef. J. Food Prot. 57:204-208.

Jacquet, C., B. Catimel, R. Brosch, C. Buchrieser, P. Dehaumont, V. Goulet, A. Lepoutre, P. Veit, and J. Rocourt. 1995. Investigations related to the epidemic strain involved in the French listeriosis outbreak in 1992. Appl. Environ. Microbiol. 61:2242-2246.

Jacquet, C., C. Saint-Cloment, F. Brouille, B. Catimel, and J. Rocourt. 1998. La listériose humaine en France en 1997. Données du Centre National de Référence des Listeria. Bull. Epidemiol. Hebdomadaire 33:142-143.

Jensen, A., W. Frederiksen, and P. Gerner-Smidt. 1994. Risk factors for listeriosis in Denmark, 1989-1990. Scand. J. Infect. Dis. 26:171-178. 
Junttila, J. R., S. I. Niemelä, and J. Hirn. 1988. Minimum growth temperatures of Listeria monocytogenes and non-haemolytic listeria. J. Appl. Bacteriol. 65:321-327.

Kathariou, S. 2002. Listeria monocytogenes virulence and pathogenecity, a food safety perspective. J. Food Prot. 65:1811-1829.

Loncarevic, S., M.-L. Danielsson-Tham, and W. Tham. 1995. Occurrence of Listeria monocytogenes in soft and semi-soft cheeses in retail outlets in Sweden. Int. J. Food Microbiol. 26:245-50.

Lukinmaa, S., M. Miettinen, U.-M. Nakari, H. Korkeala, and A. Siitonen. 2003. Listeria monocytogenes isolates from invasive infections: variation of sero- and genotypes during an 11-year period in Finland. J. Clin. Microbiol. 41:1694-1700.

Lundén, J. M., T. J. Autio, and H. J. Korkeala. 2002. Transfer of persistent Listeria monocytogenes contamination between food processing plants associated with a dicing machine. J. Food Prot. 7:1129-1133.

Lundén, J. M., T. J. Autio, and H. J. Korkeala. 2003. Persistent and nonpersistent Listeria monocytogenes contamination in meat and poultry processing plants. J. Food Prot. (accepted)

Lyytikäinen, O., T. Autio, R. Maijala, P. Ruutu, T. Honkanen-Buzalski, M. Miettinen, M. Hatakka, J. Mikkola, V.-J. Anttila, T. Johansson, L. Rantala, T. Aalto, H. Korkeala, and A. Siitonen. 2000. An outbreak of Listeria monocytogenes serotype 3a from butter in Finland. J. Infect. Dis. 181:1838-1841.

Maijala R., O. Lyytikäinen, T. Johansson, T. Autio, T. Aalto, L. Haavisto, and T. Honkanen-Buzalski. 2001. Exposure of Listeria monocytogenes within an epidemic caused by butter in Finland. Int. J. Food Microbiol. 70:97-109.

McClure, P. J., T. A. Roberts, and P. Otto Oguru. 1989. Comparison of effects of sodium chloride, $\mathrm{pH}$ and temperature on the growth of Listeria monocytogenes on gradient plates and in liquid medium. Lett. Appl. Microbiol. 9:95-99.

McLauchlin, J. 1990a. Human listeriosis in Britain, 1967-85, a summary of 722 cases. 1 . Listeriosis during pregnancy and in the newborn. Epidemiol. Infect. 104:181-189.

McLauchlin, J. 1990b. Human listeriosis in Britain, 1967-85, a summary of 722 cases. 2. Listeriosis in non-pregnant individuals, a changing pattern of infection and seasonal incidence. Epidemiol. Infect. 104:191-201.

McLauchlin, J. 1996. The role of Public Health Laboratory Service in England and Wales in the investigation of human listeriosis during the 1980s and 1990s. Food Control 7:235-239.

McLauchlin, J., S. M. Hall, S. K. Velani, and R. J. Gilbert. 1991. Human listeriosis and pâté: a possible association. Br. Med. J. 303:773-775.

McLauchlin, J., and L. Newton. 1995. Human listeriosis in England, Wales and Northern Ireland: a changing pattern of infection. Pages 177-181 in XII Int. Symp. Problems Listeriosis. Promaco Conventions Pty Ltd., Perth, Western Australia, Australia.

Miettinen, M. K., K. J. Björkroth, and H. J. Korkeala. 1999a. Characterization of Listeria monocytogenes from an ice cream plant by serotyping and pulsed-field gel electrophoresis. Int. J. Food Microbiol. 46:187-192.

Miettinen, M. K., A. Siitonen, P. Heiskanen, H. Haajanen, K. J. Björkroth, and H. J. Korkeala. 1999b. Molecular epidemiology of an outbreak of febrile gastroenteritis caused by Listeria monocytogenes in cold-smoked rainbow trout. J. Clin. Microbiol. 37:2358-2360.

Morgan, F., V. Bonnin, M.-P. Mallereau, and G. Perrin. 2001. Survival of Listeria monocytogenes during manufacture, ripening and storage of soft lactic cheese made from raw goat milk. Int. J. Food Microbiol. 64:217-221.

National Public Health Institute. 2003. Infection Register. Finland. Online. Available http://www.ktl.fi/ttr/. Accessed May 5, 2003.
National Veterinary and Food Research Institute. 1999. Examination of Listeria monocytogenes in dairy plants. Helsinki, Finland.

Nolan, D. A., D. C. Chamblin, and J. A. Troller. 1992. Minimal water activity levels for growth and survival of Listeria monocytogenes and Listeria innocua. Int. J. Food. Microbiol. 16:323-335.

Public Health Agency. 2002. Infectious and parasitic diseases in Latvia in 2002. Epidemiologijas Biletens. January, 14. Online. Available http://www.sva.lv/eng/epd/. Accessed June 16, 2003.

Rantala, L., S. Lukinmaa, A. Siitonen, and T. Honkanen-Buzalski. 2001. A national electric network for comparison of PFGE profiles of Listeria monocytogenes. Page 155 in XIV International Symposium on Problems of Listeriosis (ISOPOL). Mannheim, Germany.

Rocourt, J., C. Jacquet, F. Brouille, C. Saint-Cloment, and B. Catimel. 1997. La listériose humaine en France en 1995 et 1996. Données du Centre National de Référence des Listeria. Bull. Épidémiol. Hebdomadaire. 41:186-187.

Rocourt, J., C. Jacquet, and A. Reilly. 2000. Epidemiology of human listeriosis and seafoods. Int. J. Food Microbiol. 62:197-209.

Rudolf, M., and S. Scherer. 2001. High incidence of Listeria monocytogenes in European red smear cheese. Int. J. Food Microbiol. 63:91-98.

Ryser, E. T., and E. H. Marth. 1987. Fate of Listeria monocytogenes during the manufacture and ripening of Camembert cheese. J. Food Prot. 50:372-378.

Ryser, E. T., and E. H. Marth, ed. 1999. Listeria, Listeriosis and Food Safety. 2nd ed. Marcel Dekker, New York.

Salamina, G., E. Dalle Donne, A. Niccolini, G. Poda, D. Cesaroni, M. Bucci, R. Fini, M. Maldini, A. Schuchat, B. Swaminathan, W. Bibb, J. Rocourt, N. Binkin, and S. Salmaso. 1996. A foodborne outbreak of gastroenteritis involving Listeria monocytogenes. Epidemiol. Infect. 117:429-436.

Sauders, B. D., E. D. Fortes, D. L. Morse, N. Dumas, J. A. Kiehlbauch, Y. Schukken, J. R. Hibbs, and M. Wiedmann. 2003. Molecular subtyping to detect human listeriosis clusters. Emerg. Infect. Dis. 9:672-680

Schlech, W. F., P. M. Lavigne, R. A. Bortolussi, A. C. Allen, E. V. Haldane, A. J. Wort, A. W. Hightower, S. E. Johnson, S. H. King, E. S. Nicholls, and C. V. Broome. 1983. Epidemic listeriosis: evidence for transmission by food. N. Engl. J. Med. 308:203-206.

Schlech, W. F. 2000. Foodborne listeriosis. Clin. Infect. Dis. 31:770-775.

Seeliger, H. P. R. 1961. Listeriosis. Hafner, New York.

Seeliger, H. P. R., and D. Jones. 1986. Listeria. Pages 1235-1245 in Bergey's Manual of Systematic Bacteriology. Williams and Wilkins, Baltimore.

Swaminathan, B., T. J. Barrett, S. B. Hunter, and R. V. Tauxe. 2001. PulseNet: the molecular subtyping network for foodborne bacterial disease surveillance, United States. Emerg. Infect. Dis. 7:382-389.

Tham, W., E. Bannerman, J. Bille, H. Ericsson, S. Helmersson, B. Henriques, C. Jacquet, S. Loncarevic, J. Rocourt, I. Tjernberg, H. Unnerstad, and M.-L. Danielsson-Tham. 2001. Changes in serogroup distribution of human Listeria monocytogenes strains in Sweden. Page 149 in XIV Int. Symp. Problems Listeriosis (ISOPOL). Mannheim, Germany.

Unnerstad, H., E. Bannerman, J. Bille, M.-L. Danielsson-Tham, E. Waak, and W. Tham. 1996. Prolonged contamination of a dairy with Listeria monocytogenes. Neth. Milk Dairy J. 50:493-499.

Waak, E., W. Tham, and M.-L. Danielsson-Tham. 2002. Prevalence and fingerprinting of Listeria monocytogenes strains isolated from raw whole milk in farm bulk tanks and in dairy plant receiving tanks. Appl. Environ. Microbiol. 68:3366-3370.

World Health Organization Working Group. 1998. Foodborne listeriosis. Bull. WHO 66:421-428. 